\title{
What Drives Performance Budgeting to Perform? A Survey Examination in Taiwan
}

\author{
Louis Chih-hung Liu ${ }^{1}$ \\ ${ }^{1}$ Department of Public Administration, Tamkang University, Taipei, Taiwan \\ Correspondence: Louis Chih-hung Liu, Department of Public Administration, Tamkang University, Tamsui, \\ 25137, Taiwan. Tel: 1-886-22-621-5656(3383). E-mail: louisliu@mail.tku.edu.tw
}

Received: May 14, 2013 Accepted: May 20, 2013 Online Published: September 29, 2013

doi:10.5539/par.v2n2p58 URL: http://dx.doi.org/10.5539/par.v2n2p58

\begin{abstract}
This article attempts to investigate whether the international experiences generated from the success stories of advanced economies would also be recognized in the emerging markets. Generally speaking, budget experts around the globe are contending that performance budgeting would be properly put to work under the assistance of Medium-Term Expenditure Framework, fiscal transparence and other institutional arrangements. Based on this analytical framework, we employ the method of survey instrument to explore whether these assertions are also accepted in the emerging markets. The selective country case is Taiwan, one of the most successful emerging markets. We then justify our survey results by conducting confirmatory factor analysis (CFA). While there is high consensus over these international experiences in Taiwan, respondents in different categories feature slightly different attitude. Our survey results reveal that experts in academia are more affirmative toward these auxiliary institutional arrangements for performance budgeting compared to the practitioners in selective government's agencies.
\end{abstract}

Keywords: confirmatory factor analysis, fiscal transparency, MTEF, performance budgeting, TAIWAN

\section{Introduction}

Budgetary reform, i.e., budgetary evolution and flexible financial management, has become a worldwide trend both in developed and developing countries that are looking to improve efficiency and effectiveness in the public sector (Cheung, 2006). The past few decades have seen a series of budgeting reforms taking place in governments around the world. Since the 1990s, performance budgeting has been widely touted as the mainstream in budgeting reforms around the globe. From the initial difficulties in measuring performance in the public sector (Berman \& Wang, 2000) and nonprofit organizations (Roh et al., 2010) to the establishment of guidelines for worldwide governmental reform, the implementation of performance budgeting seems to have experienced smooth sailing and become the cornerstone of movements to reinvent the government either locally or nationally. For example, Melkers and Willoughby $(1998,2001)$ have identified that 47 out of 50 states in America have performance budgeting requirements. Several OECD (Organization for Economic Cooperation and Development) member countries also initiated budgeting reforms targeting the performance-related mechanism so as to strengthen public accountability. Following the successful international experience of advanced economies, international organizations, such as the OECD and IMF (International Monetary Fund), are also endeavoring to promote the idea of performance budgeting as a priority in the government reform and development strategy in the developing world.

Despite its ever-growing popularity in the public expenditure reform around the globe, the practice of performance budgeting still embodies several impediments for developing countries and exhibits an elevated failure rate in the course of the reform. While some countries are making remarkable headway in performance-based budgeting, others are still struggling to survive in this experimental approach.

Recognizing the relationship between performance budgeting, fiscal transparency and Medium-Term Expenditure Framework (MTEF), international organizations endeavor to advocate these institutional reforms in developing world. In spite of their intrinsically related nature, the associations between performance budgeting, fiscal transparency and MTEF are rarely discussed in the emerging markets. Therefore, in this paper, a survey instrument is conducted to inquire from experts and practitioners in governments as well as in academia as to whether they have agreements in these critical conditions that might be essential to the success of performance budgeting. The 
reasons for choosing Taiwan as a case study in our research abound. Taiwan is one of the most successful emerging market economies with mostly traditional budgeting practices but very strong executive and planning agencies. Furthermore, Taiwan has undergone massive budget reform since 1990s, primarily due to the deteriorating fiscal condition. All these policy prescriptions on budgetary institutions render Taiwan as a good target for our research. We will discuss all these institutional reforms in Taiwan at section III.

In brief, most of the academic literature deals with the process and impact of performance budgeting reform in developed countries (Wang, 2002). Nonetheless, several of these studies with their discussions on performance budgeting are largely normative assertions. This paper is an exploratory research and our study attempts to examine whether these critical conditions identified by international experiences for successful performance budgeting is also recognized in Taiwan. This research plays a pioneer role in conducting a survey to examine people's attitude towards performance budgeting implementation in Taiwan. Furthermore, different from the previous normative study on performance budgeting, we employ innovative CFA analytical approach to validate our survey instrument and further to investigate how these identified institutional arrangements associate with each other.

\section{Literature Review and Analytical Framework}

The essence of performance budgeting highly depends on accurate performance measurements for increasing accountability and thus improving government performance. Nevertheless, myriad difficulties have been recognized, such as uncertain stakeholder support and inadequate technical ability to collect and analyze performance data (Berman \& Wang, 2000). Besides, OECD (2009: 269) contends that "budgeting is part of a grid of interconnected practices and process that cannot be reshaped without also restructuring the management framework within which financial resources are spent and activities carried out." The auxiliary institutional arrangements are hence ever more important for the successful implementation of performance budgeting.

\subsection{Fiscal Transparency}

Fiscal Transparency refers to the practice of public disclosure of governmental fiscal activities. The emergence of fiscal transparency is primarily due to the complexity of the budgeting and fiscal system of modern nations and the tendency of politicians to exploit common goods. Thus, nowadays transparency of the fiscal system is a goal pursued by governments around the globe. Alesina and Perotti (1996) have properly elucidated two theoretical arguments as to why politicians have little incentive to produce simple, clear, and transparent budgets. The first is the theory of fiscal illusion, which stipulates that voters always overestimate the benefits of public spending and underestimate the cost of taxation. The second argument highlights the benefits of an ambiguous budget, which may facilitate the opportunistic behavior adopted by politicians even when they face a rational but partially informed electorate. With these assertions in mind, the significance of fiscal institutions with respect to transparency can no longer be ignored.

Other than the constraint of politicians overestimating the benefits of expansionary public expenditure, Islam (2006) further contended that better governance is brought about by transparency. His analysis of cross-country data suggests that countries with better information flows usually have better governance. In brief, fiscal transparency not only prevents the irresponsible spending behavior resulting from asymmetric information but also associates with better governance in governments in general. Increasing fiscal transparency is a way of providing stakeholders in government activities with more information regarding the intentions behind the fiscal policy, which alleviates the task of forecasting future fiscal movements (Alt et al., 2006).

\subsection{Medium-Term Expenditure Frameworks (MTEF)}

Besides fiscal transparency, the MTEF is also employed by international organizations as a development strategy for promoting developing countries' economic status. According to the World Bank definition, "the MTEF consists of a top-down resource envelop, a bottom-up estimation of the current and medium-term costs of existing policy and, ultimately, the matching of these costs with available resources... in the context of the annual budget process" (World Bank, 1998: 46; Houerou \& Taliercio, 2002: 2). In other words, rather than formulate the budget schedule annually, the MTEF requests governments to plan and program the public expenditure in a multiyear framework.

While the MTEF is argued to be an ideal policy tool to facilitate such outcomes as greater macroeconomic balance, improved resource allocation, more accurate budgetary predictability, and greater efficiency in public expenditure, several developing countries have encountered problems associated with the lack of adequate human resources or management skills required for implementing such institutional reforms. This is why several international organizations are making efforts to encourage the enabling of this institutional reform throughout the developing 
world as the MTEF is undeniably a long-term goal worthy of pursuit. However, just like fiscal transparency, the MTEF cannot be treated as a single restructuring program in isolation from other basic budgetary reforms since it focuses principally on budget formulation issues (Houerou \& Taliercio, 2002: 5). Other major issues with respect to budget execution, reporting, and auditing should also be addressed, which makes other budgetary institutional reforms necessary.

\subsection{Performance Budgeting, Fiscal Transparency, and MTEF}

The connection between these three public sector reforms may not be so obvious at first glance. The MTEF refers to the method of integrating policy, planning, and budgeting within a medium-term perspective. The OECD defined performance budgeting as budgeting that links the fund allocated to measureable results (OECD, 2008a). Lastly, the fiscal transparency adopted in advanced economies mainly suggests the public disclosure of all relevant fiscal information on a systematic and timely basis. How might these three components be related? In the following paragraphs, we briefly explore the relationship between them.

While some scholars argue that performance budgeting should be based on the mechanism of the MTEF and fiscal transparency as well, others assert the opposite connection among these elements for government reform. Cho (2004) made the contention that the financial management information system (FMIS) must be able to provide the necessary financial and performance information if the MTEF reform is to succeed. In addition, the IMF also proposed that the way to strengthen fiscal transparency in a country is through the introduction of a MTEF budget and a forward-looking analysis of fiscal policy that emphasizes sustainability and medium-term policy goals (Parry, 2008). Furthermore, Arnold (2008) argued that performance budgeting was meant to increase government transparency for major stakeholders - Congress and the public.

Regardless of the causal relation of these three elements regarding performance budgeting reform, we can derive some clues that these elements are highly associated. Dorotinsky (2004) also attempted to explore the associations among the MTEF, performance budgeting, and transparency. He argued that the MTEF strengthens performance budgeting by providing more predictability in resource flows to programs that facilitate planning and budgeting, thus giving them more relevance. Furthermore, the MTEF is also able to change incentives in the budget process by implementing hard budget constraints over spending ministries, which prompts them to find savings for reallocation to higher priority programs.

\subsection{Some Agreements from International Experience}

Performance budgeting is easy to explain but very difficult to implement (Schick, 2007: 122). As a result, international organizations endeavor to facilitate its implementation by enacting some guidelines for initiating performance budgeting in developing countries. The OECD (2008b: 4) has drafted the sequence of implementing performance budgeting by indicating the following procedures as prerequisites:

1. Developing a program budget classification: Countries agreed that it is necessary to have a good knowledge of their program base in order to implement performance budgeting.

2. Developing a performance information system: The type of information and systems developed should depend on how the reformers intend to use such information. Is it to be closely linked to budget decisions and overall administrative efficiency? Or is it to be used for monitoring government programs and promoting public accountability for results?

3. Linking a MTEF with performance budgeting: Medium-term expenditure frameworks can improve transparency and facilitate greater prioritization of government objectives.

In addition to these prerequisites widely accepted and highly recommended by advanced economies, Schick (2008) pointed out that the interdependence of governance, management, and budgeting has been confirmed by international experience. Those countries with successful performance budgeting implementation usually have the following characteristics: low corruption, efficient public administration, effective accountability arrangements, political and administrative channels for citizens to express preferences and grievances, and procedures for monitoring the quality of public services (Schick, 2008: 18). Hence, the first step to performance reform for developing countries might be to remove the barriers that hinder the development of performance management. In this regard, Schick suggested diagnosing the countries' deficiencies by following the Code of Good Practices on Fiscal Transparency and the PEFA (Public Expenditure and Financial Accountability) questionnaire developed by international organizations (Schick, 2008: 21).

The involvement of other elements is also vital to the implementation of performance budgeting. Willoughby and Melkers (2000) argued that modern budget reform should facilitate communication between the government and citizens. Lee (1997) also contended that greater communication among the executive and legislative branch 
members and the citizens is useful for the development of such performance measurements.

\section{Budget Reform in Taiwan}

During the economic boom in 1980s, Taiwan had a balanced and well-organized fiscal structure. Moreover, foreign direct investments in the island were also increasing significantly. The revenue side of the government was thus expanding at a double-digit rate, which made Taiwan's fiscal performance a model for the Asia-Pacific region. For a while, the term "budget deficit" seemed to be unheard of in Taiwan. Nevertheless, after stepping into the 1990s, with the approach of the worldwide recession and economic bubble which had gone bust, the central government in Taiwan encountered a shortage of money and a sporadic budget deficit. In the meantime, the ratio of government debt to GDP was soaring, along with a diminishing ratio of tax revenue to GDP. Hence, the government was forced to adopt austere measures to correct its deteriorating fiscal condition and maintain fiscal sustainability.

In order to successfully cope with the issues of public finance, the government must adapt to its worsening fiscal condition, which may ultimately lead to dire economic consequences for the country. Accordingly, the central government in Taiwan is pondering the transformation of the traditional public budgeting that has usually displayed strong characteristics of incremental budgeting. The traditional way of bottom-up budget preparation by the subordinating agency is no longer taken for granted. In 1995, the central government made the announcement that a new top-down approach, the Public Expenditure Quota System (PEQS), had been initiated. This new budget control mechanism imposed individual expenditure ceilings on all ministries at the very beginning of the annual budget formulation stage. All the subordinating agencies must follow the annual expenditure caps set by the central government.

Aside from the measure of the PEQS, the legislative branch also enacted the Public Debt Act in 1996 in order to tackle the problem of skyrocketing national debt. The Act stipulated two layers of regulations on the public debt ceilings, which is believed to properly restrain the ever-increasing public debt level. First, the total outstanding public debt at all levels of government cannot exceed $48 \%$ of the average GNP of the previous three years. Second, the annual budget deficit of each government level cannot exceed $15 \%$ of that level's total expenditure for the year (Su, 2007: 335).

With respect to the measures associated with performance budgeting, the so-called Medium-Term Plans Budgeting System (MTPBS) (Note 1) was launched by central government to serve as the auxiliary institutional arrangements for the Administrative Regulations of Performance Assessment for Agencies (ARPAA), the official title of performance-based budgeting in Taiwan. Under the requirements of ARPAA, each agency under the central government is guided by the performance objectives, performance indicators, and performance targets in three major areas: services, manpower, and funding (Lee \& Wang, 2009: 63). With three tiers of performance management mechanism utilized, staffs in the government are highly motivated by these guidelines. To ensure the implementation of performance budgeting, each agency is under assessment with regard to its performance results and its designated performance objectives.

There seems to be no difference between performance budgeting in Taiwan and performance budgeting elsewhere. Nevertheless, two distinct features of Taiwan's performance budgeting can be properly drawn from previous studies (Lee \& Wang, 2009). One is the strong executive-led performance budgeting which necessitate constant evaluation on all agencies annually and repeatedly. This feature also highlights the discrepancy between respondents from executive branch and legislative branch. The other feature is Taiwan's performance budgeting exhibits a carefully designed project management process in which each project is subject to intensive administrative scrutiny during planning, implementation and evaluation.

The modifications of the Budget Act in 1998 are regarded as giant step toward fiscal transparency in Taiwan. Su (2007: 339) points out the following amendments as Taiwan endeavors to realize fiscal transparency:

1. Annual budget documents should include estimates of tax expenditure and transfer payments (Article 29).

2. Major public infrastructure spending should be accompanied by cost benefit analysis (Article 34).

3. All annual revenue and expenditure should be presented based on international accounting standards (Article $6)$.

In addition to the abovementioned efforts, Taiwan's government has also already made all budget documents and relevant fiscal information publicly available, free of charge, and downloadable on the web.

Several observations and conclusions can be drawn from the analysis above. First, the top-down character of the budget process is pronounced in Taiwan, particularly after 1995, where there is a high concentration of policy and 
fiscal powers at the top of the executive branch not only vis-à-vis the lower levels but also vis-à-vis the legislative branch. Second, the strategic capacity of the Taiwan government seems to be well developed. In effect, the government is successful in using the budget as a tool in achieving the ambitious objectives of Taiwan's developmental state.

Third, Taiwan's legislative provision, which prohibits the expansion of expenditures by the legislature on popular demand of constituencies, contributes to sound fiscal probity. This is distinct from the old incremental due process in budgeting where the process starts with individual agencies' claims over the resources, leading to the "tragedy of commons" problem.

Furthermore, budget reforms undertaken in Taiwan seem to follow the path of successful experience generated from advanced economies. Taiwan's government attempt to modernize its budget institutions through internationally endorsed practices. As we have already indicated, this movement in Taiwan has rendered it a good case study in performance budgeting research.

\section{Research Design}

Based on previous literature and practitioner experiences, we acknowledge that several institutional prerequisites have been identified by experts from past international experience. In this research, however, we attempt to investigate whether these characteristics agreed on by international organizations would also exhibit high consensus in emerging markets. Our methodology is to inquire from professional practitioners and academic experts in the related fields through a survey instrument. Each question in the instrument is designed and formulated based on the aforementioned institutional arrangement prerequisites. The interviewees are given a questionnaire with a list of four factors related to performance budgeting.

The questionnaire is designed primarily based on these four factors (please refer to Appendix I). The first factor is about the perception or understanding of performance budgeting. The second factor is about the role of fiscal/budget transparency in performance budgeting. The third factor is mainly focused on how the MTEF interacts with performance budgeting. The fourth factor concerns other institutional arrangements that might be essential to implementing performance budgeting. While we have acknowledged the multiple dimensions of fiscal transparency and the MTEF, we are unable to include all the contexts of both into the questionnaire as there are numerous requirements in the practice protocol of fiscal transparency and the MTEF. Hence, we selected representative questions that properly capture each dimension of fiscal transparency and the MTEF to inquire about the respondents' attitudes toward the issues under study. Taking fiscal transparency for instance, we employ the four-dimension methods provided by Report on the Observance of Standards and Codes (ROSC), an official report published by IMF. The four dimensions identified are: clarity of roles and responsibilities, open budget process, public availability of information, and independent assurances of integrity. Based on the four dimensions of fiscal transparency, we then assign selective questions for each dimension. With respect to the questions on other institutional arrangements, we mainly depicted them based on the World Bank publications (Shah \& Shen, 2007a: 171-175; Shah \& Shen, 2007b: 162-166).

The measurement for respondents' attitude is based on a Likert scale, which is a psychometric scale commonly used in questionnaires and the most widely used scale in survey research. In our questionnaire, a five-level Likert item is drafted to inquire into the subjective attitude toward performance budgeting. Each interviewee is asked to indicate how important they considered each factor to be. In our survey questions, we have chosen to phrase the stem in a positive direction for the convenience of analysis. Some may concern the same order items would be controversial due to the occurrence of affirmative bias. Nevertheless, our survey respondents exhibit high interest and professionalism in this topic and would respond each question carefully and thoughtfully. The affirmative bias can be diminished with our specific audience's participation in this survey (Colton \& Covert, 2007: 190).

Our target survey takers include practitioners and experts in public finance and budgeting at the central government in Taiwan since the context in the questionnaire is associated with high-level professional knowledge. Consequently, the staff at the Budgeting Center in the Legislative Yuan (CBO-like agency), the DGBAS (Directorate-General of Budgeting, Accounting, and Statistics) in the Executive Yuan (OMB-like agency), and the Ministry of Auditing in the Control Yuan (GAO-like agency) make up our potential sample for observation. These survey respondents, i.e. budgeters at legislative and executive branch, are highly utilized as survey targets by several researchers (Berman \& Wang, 2000; Melkers \& Willoughby, 1998; Melkers \& Willoughby, 2001; Melkers \& Willoughby, 2005; Willoughby \& Melkers, 2000). We particularly interested in the respondents from executive and legislative branch as previous studies have attempted to explore the impacts brought about by performance budgeting on executive as well as legislative staffs (Gilmour \& Lewis, 2006; Sterck, 2007). In addition to practitioners in the government, professionals in academia/universities are also among our primary survey 
respondents in order to acquire a holistic view of performance budgeting implementation.

\section{Empirical Results}

Before presenting our survey results, several procedures are used to guarantee the credibility of our survey instrument as our major analysis results are based on this originally designed survey. First, as mentioned above, survey questions are designed to ensure their pertinence to the associations between performance budgeting and other institutional arrangements. Second, survey respondents are randomly selected from experts in governments as well as academia, due to the sophistication and professionalism in the survey questions. Third, reliability and validity tests are conducted to guarantee that our survey results are properly measured. We delivered 200 questionnaires for our study. While we endeavored to collect as many questionnaires as we could, only 112 respondents kindly sent back their answers. In the following paragraphs, we will illustrate our empirical results.

\subsection{Reliability and Validity: A Confirmatory Factor Analysis}

We conduct confirmatory factor analysis (CFA) based on the sample observations we garnered from this research. Our first step of CFA is to examine each factor's reliability; then, we regard the whole survey as a general CFA model and investigate goodness-of-fit statistics of the model. Our primary statistical software is Amos 20 version. The CFA for each factor is intended to identify whether every question in our survey is adequately capture the content of designated factor. We present our single factor analysis results in table 1.

In table 1, factor loadings (Standard Estimate) are all ranging above 0.5 while the composite reliability for each factor is above 0.6. Fornell \& Larcker (1981) suggested that a composite reliability above 0.6 is acceptable. In addition to the single factor reliability test, we also investigate the whole CFA model goodness-of-fit statistics. Figure 1 demonstrated the diagram of the three correlated factors along with goodness-of-fit statistics (at the bottom of figure 1). Our model goodness-of-fit statistics indicate that our general model is largely consistent with the recommended value by previous studies. The recommended value range of each indicator, i.e. GFI, AGFI (Note 2), RMSEA, may refer to table 1. As a consequence, we conclude our general model is feasible in terms of soliciting information from this exploratory research.

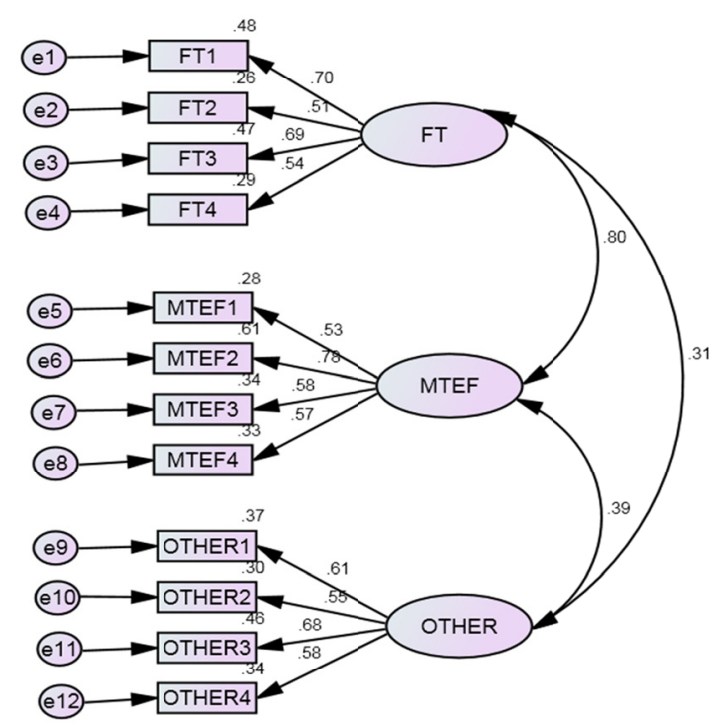

\footnotetext{
Chi-square $=65.696 \mathrm{P}$-value $=.081$

Degreeoffreedom $=51 \times 2 / \mathrm{df}=1.288$ $\mathrm{GFI}=.916 \mathrm{AGFI}=.871$

RMSEA $=.051$
}

Figure 1. General CFA Model Goodness-of-Fit 
Table 1. CFA analysis results: reliability and model fit

\begin{tabular}{|c|c|c|c|c|c|c|c|c|c|c|c|c|c|c|}
\hline \multirow[b]{2}{*}{ Indicators } & \multirow[b]{2}{*}{ Factors } & \multicolumn{4}{|c|}{ Model Parameter Estimates } & \multicolumn{3}{|c|}{ Reliability Test } & \multicolumn{6}{|c|}{ Goodness-of-Fit Statistics } \\
\hline & & Estimate & S.E. & $\begin{array}{r}\text { C.R.* } \\
\text { (t-value) }\end{array}$ & $\mathrm{P}$ & $\begin{array}{c}\text { Std. Est. } \\
(>0.5)\end{array}$ & $\begin{array}{c}\text { SMC } \\
(>0.3)\end{array}$ & $\begin{array}{l}\text { C.R.** } \\
(>0.6)\end{array}$ & $X^{2}$ & DF & $\begin{array}{l}\mathrm{X}^{2} / \mathrm{DF} \\
(1 \sim 3)\end{array}$ & $\begin{array}{r}\text { GFI } \\
(>0.9) \\
\end{array}$ & $\begin{array}{l}\text { AGFI } \\
(>0.8)\end{array}$ & $\begin{array}{l}\text { RMSEA } \\
(<0.08)\end{array}$ \\
\hline FT4 & $<---$ FT & 0.951 & 0.205 & 4.643 & $* * *$ & 0.634 & 0.402 & \multirow{4}{*}{0.708} & \multirow{4}{*}{2.005} & \multirow{4}{*}{2} & \multirow{4}{*}{1.002} & \multirow{4}{*}{0.991} & \multirow{4}{*}{0.957} & \multirow{4}{*}{0.005} \\
\hline FT3 & $<---$ FT & 0.923 & 0.197 & 4.692 & $* * *$ & 0.656 & 0.430 & & & & & & & \\
\hline FT2 & $<---$ FT & 0.608 & 0.159 & 3.875 & $* * *$ & 0.505 & 0.2550 & & & & & & & \\
\hline FT1 & $<---$ FT & 1 & & & & 0.680 & 0.462 & & & & & & & \\
\hline MTEF4 & $<---$ MTEF & 1 & & & & 0.598 & 0.391 & \multirow{4}{*}{0.721} & \multirow{4}{*}{5.016} & \multirow{4}{*}{2} & \multirow{4}{*}{2.508} & \multirow{4}{*}{0.978} & \multirow{4}{*}{0.892} & \multirow{3}{*}{0.112} \\
\hline MTEF3 & $<---$ MTEF & 0.944 & 0.227 & 4.162 & $* * *$ & 0.552 & 0.526 & & & & & & & \\
\hline MTEF2 & $<---$ MTEF & 1.439 & 0.309 & 4.659 & $* * *$ & 0.725 & 0.304 & & & & & & & \\
\hline MTEF1 & <--- MTEF & 0.908 & 0.203 & 4.482 & $* * *$ & 0.625 & 0.357 & & & & & & & \multirow{5}{*}{0.092} \\
\hline OTHER4 & $<---$ OTHER & 1 & & & & 0.6 & 0.352 & \multirow{4}{*}{0.697} & \multirow{4}{*}{3.89} & \multirow{4}{*}{2} & \multirow{4}{*}{1.95} & \multirow{4}{*}{0.983} & \multirow{4}{*}{0.915} & \\
\hline OTHER3 & <--- OTHER & 1.067 & 0.246 & 4.337 & $* * *$ & 0.689 & 0.282 & & & & & & & \\
\hline OTHER2 & <--- OTHER & 0.858 & 0.22 & 3.906 & $* * *$ & 0.531 & 0.475 & & & & & & & \\
\hline OTHER1 & <--- OTHER & 1.066 & 0.256 & 4.166 & $* * *$ & 0.593 & 0.36 & & & & & & & \\
\hline PERC3 & $<---$ PERC & 1 & & & & 0.768 & 0.59 & \multirow{3}{*}{0.868} & \multirow{3}{*}{--} & \multirow{3}{*}{--} & \multirow{3}{*}{-- } & \multirow{3}{*}{-- } & \multirow{3}{*}{--} & \multirow{3}{*}{-- } \\
\hline PERC2 & $<---$ PERC & 1.572 & 0.176 & 8.945 & $* * *$ & 0.934 & 0.873 & & & & & & & \\
\hline PERC1 & $<---$ PERC & 1.235 & 0.146 & 8.483 & $* * *$ & 0.778 & 0.605 & & & & & & & \\
\hline
\end{tabular}

*stands for "Critical Ratio".

$5 * *$ stands for "Composite Reliability". 
Aside from general model goodness-of-fit statistics, we also conduct discriminant validity and cross validity test to ensure the credibility of our survey. Discriminant validity test allows us to recognize whether each factor is highly correlated. Highly correlated factors may result in the multi-collinearity problem in multiple regression models. However, our research is not intended to run regression analysis; the multi-collinearity problem does not constitute our major concern. Torkzadeh et al. (2003) suggested the lower and upper value range of three indicators, i.e. $\psi \pm 1.96 \sigma$, Bias-corrected, and Percentile method, should not include value of 1 in order to discriminate each factor's efficacy.

Table 2. CFA analysis results: discriminant validity

\begin{tabular}{llllccccccc}
\hline Factors & Correlations & \multicolumn{4}{c}{$\psi$} & \multicolumn{3}{c}{$\psi \pm 1.96 \sigma$} & \multicolumn{3}{c}{ Bias-corrected } & \multicolumn{3}{c}{ Percentile method } \\
\hline & & & SE & Mean & \multicolumn{1}{c}{ Lower } & Upper & Lower & Upper & Lower & Upper \\
FT & $<-->$ & MTEF & 0.087 & 0.803 & 0.632 & 0.974 & 0.578 & 0.946 & 0.619 & 0.960 \\
MTEF & $<-->$ & OTHER & 0.17 & 0.399 & 0.066 & 0.732 & 0.067 & 0.751 & 0.065 & 0.749 \\
FT & $<-->$ & OTHER & 0.177 & 0.327 & -0.02 & 0.674 & -0.021 & 0.667 & -0.011 & 0.680 \\
\hline
\end{tabular}

Bootstrap $=1000$

Table 2 displayed the value range within three indicators. These three indicators all exclude value of 1 , which suggest that our CFA model exhibits discriminant validity. However, factors between FT and MTEF demonstrate discriminant value closed to 1 which might indicate these two factors are related. Cross validity test enables us to examine the measurement invariance at different group of survey respondents. We randomly divided our sample observations into two groups and assess whether the two survey results are the same.

Table 3. CFA analysis results: cross validity

\begin{tabular}{lccccc}
\hline & DF & $\mathbf{X 2}$ & P-value & ACFI( $\leqq \mathbf{0 . 0 1})$ & $\Delta$ TLI $(\leqq \mathbf{0 . 0 5})$ \\
\hline Measurement weights & 9 & 9.617 & 0.382 & 0.002 & -0.014 \\
Structural covariances & 6 & 4.095 & 0.664 & 0.007 & -0.011 \\
Measurement residuals & 12 & 11.435 & 0.492 & 0.002 & -0.017 \\
\hline
\end{tabular}

$\mathrm{H}_{0}$ : Model1 $=$ Model2

Table 3 demonstrated that $\mathrm{p}$-value is unable to reject our null hypothesis $\left(\mathrm{H}_{0}\right.$ : model $1=$ model2), suggesting our measurement invariance is established. Furthermore, $\triangle \mathrm{CFI}$ is desirable under the recommendation by Cheung \& Rensvold (2002) and $\Delta$ TLI is also within the value range suggested by Little (1997). In sum, our general CFA model is in accordance with desirable statistical factor analysis in terms of its reliability, discriminant validity, and cross validity. Hence, with current reliability and validity, we are quite confident in our empirical results presented in the next section.

\subsection{Empirical Findings}

Among the 112 respondents, we collected personal information with respect to their gender, educational background, related professional work experience, and so forth. We summarize this information on our survey takers as follows.

\section{Descriptive Analysis}

1. Gender: Around half of the participants in the survey were male. Nonetheless, there seems to be little difference over the attitude toward performance budgeting's auxiliary institutional arrangements between male and female respondents. We, thus, skip this variable in the following inferential analysis.

2. Education: More than half of the respondents hold bachelor degrees, followed by those with master and doctor degrees. Respondents with a high school diploma occupy the smallest proportion.

3. Experience: A majority of participants possess related work experience of less than 10 years, while a few of 
the respondents have worked more than 10 years in a related job. The proportion of professional work experience indicates that performance budgeting is still new to most of the practitioners.

4. Field: Respondents from the executive and legislative branches make up the majority, while participants from auditing offices and academia consist of a minority portion.

With respect to the outcome of the survey, Appendix I demonstrates the high scores for each question, which indicate that the agreements from international experience regarding the successful implementation of performance budgeting are largely in accord with those of the professionals in Taiwan.

In spite of the high consensus over the execution of performance budgeting in advanced economies, some slight disparities are still revealed in our survey result. First, in the performance budgeting perception, respondents are mostly agree that performance budgeting should be implemented domestically. Some people seem to be less informed of the existence and practice of performance budgeting in OECD member countries.

Second, there seems to be an attitude that fiscal transparency is even more important than the MTEF, based on the survey scores, in putting performance budgeting to work, as fiscal transparency factor exhibits slightly higher score than MTEF score. Besides, the attitude consistency is quite similar on the basis of their standard deviations. Among the MTEF mechanisms, the measure of "development for future projections of the expenditure ceiling in all ministries" is the least welcome by the respondents. The possible explanation for this outcome may be owing to the time-consuming and labor-intensive nature for this reform measure. The implementation of similar reform measure would ultimately augment the workload of these stakeholders.

Third, other institutional arrangements, such as support from agency leaders and professional capabilities, are also highly approved and regarded as equally significant as fiscal transparency factor by the respondents. These institutional arrangements are also the so-called "stakeholder capacity", described by Berman \& Wang (2000: 410). Nevertheless, civic engagement is the least desirable condition for performance budgeting. A possible explanation for this result may be ascribed to the distrust in civil participation in the sophisticated nature of performance budgeting.

\section{Inferential Analysis}

After the aforementioned descriptive analysis, we further conducted inferential statistical analysis to examine the associations between personal information and each factor of performance budgeting. The methodology employed was one-way ANOVA. This approach allows us to explore whether there is any significant association between the survey respondents' backgrounds, i.e., education, professional field, and professional experience, and their attitudes toward various institutional arrangements for performance budgeting. A post-hoc test with the least significant difference (LSD) is further conducted if a significant F-value is found. The post-hoc test enables us to distinguish intergroup differences in selected personal information.

Table 4. One-Way ANOVA analysis

\begin{tabular}{ccccc}
\hline $\begin{array}{c}\text { Personal } \\
\text { Information }\end{array}$ & Education & $\begin{array}{c}\text { Professional } \\
\text { Experience }\end{array}$ & $\begin{array}{c}\text { Professional } \\
\text { Field }\end{array}$ \\
\hline Perception & F-value & $5.515^{* * *}$ & 0.066 & $6.009^{* * *}$ \\
& Post-hoc & $4>2$ & N.A. & $1<2,4$ \\
Fiscal Transparency & F-value & $23.622^{* * *}$ & 1.532 & $16.870^{* * *}$ \\
& Post-hoc & $4>1,2,3$ & N.A. & $4>1,2,3$ \\
MTEF & F-value & $21.467^{* * *}$ & 1.509 & $15.032^{* * *}$ \\
& Post-hoc & $4>1,2,3$ & N.A. & $4>1,2,3$ \\
Others & F-value & $5.515^{* * *}$ & 0.066 & $6.009 * * *$ \\
& Post-hoc & $4>2$ & N.A. & $1<2,4$ \\
\hline
\end{tabular}

Note: $* * * \mathrm{P}<.001$

In the following paragraphs, we present the ANOVA results between institutional factors and personal information. 
The ANOVA results are illustrated in Table 4. We did not include gender in the analysis as this variable does not play a significant role and exhibits little discrepancy in our statistical analysis. One thing needs to be pointed out is that we find there is certain degree of similarity between two variable: Education and Professional Field because their ANOVA results are quite parallel. A possible explanation is that most doctoral degree holders in our survey are in the field of academia. Few of them are in the government, i.e., the executive, legislative, and auditing branches.

Perception: Two personal information variables (education and field) exhibit statistical significance. A post-hoc test suggests that respondents with a doctoral degree and those in the academic field have a better understanding of performance budgeting than all their counterparts. This result is largely consistent with our expectation as the concept and practice of performance budgeting were introduced by professionals from academia in Taiwan. In addition, professionals or practitioners from legislative demonstrate a better understanding of performance budgeting than the counterparts in executive branch.

1. Fiscal Transparency: Two personal information variables, education and professional field, exhibit significance. A post-hoc test suggests that compared to all their counterparts, respondents with a doctoral degree and those from academia hold more approving attitudes of the view that fiscal transparency is important for the successful implementation of performance budgeting. This result is also consistent with our expectation.

2. MTEF: Regarding the viewpoint on the importance of the MTEF in performance budgeting, the result is almost the same as that on the importance of fiscal transparency in performance budgeting.

3. Other Institutional Arrangements: The result of other institutional arrangements is the same as that on the perception of performance budgeting. Respondents with a doctoral degree still hold a stronger attitude of consent than counterparts with bachelor degree. In terms of professional field, legislative professionals are more affirmative than executive professionals.

Judging from the aforementioned arguments and examples, we discover that respondents with doctoral degrees or from academia hold a more positive attitude toward these institutional arrangements, as primarily observed from the experience of advanced economies. Somehow, this empirical finding is not beyond our expectation since most budgeting reforms in Taiwan are based on the advice of professionals from academia. A majority of professionals from academia receive their training and knowledge from abroad, mainly from developed countries. Moreover, while previous studies have illustrated the impact of performance budgeting on executive as well as legislative (Gilmour \& Lewis, 2006; Sterck, 2007), our ANOVA analysis seems to suggest that impact on executive is more severe than that on legislative as professionals from executive exhibit a less confirmatory attitude toward the understanding and implementation of performance budgeting.

\subsection{Limitations}

Although the research is noted for its innovation in CFA analytical approach, there are constraints placed upon it due to some inherent limitations, as we noted here. Data insufficiency is one of these limitations. As we have emphasized in the previous section that our survey respondents are all highly professional experts in the related field. This prerequisite also constrains our attempts to expand sample observations. While DeCoster (1998) suggests the minimal sample size for CFA analysis is around 200, Loehlin (1987) takes the view that sample size of 100 is the least requirement. Bentler \& Chou (1987) put it in a different perspective and recommend that sample sizes at least five times of the number of parameters estimated are desirable. Even though our sample observations meet the minimum requirement proposed by several studies, insufficient sample size remains our major concern of this CFA analysis.

Followed by the data insufficiency, some of our model fit index is not perfect either. For example, RMSEA (Root Mean Square Error of Approximation) value for our single factor analysis at Table 1 is not satisfied. The possible explanation for this high RMSEA in our CFA single factor may be owing to limited sample size (Fan et al., 1999). Nevertheless, while there are some minor deficiencies in single factor model fit index, our general CFA model presented at figure 1 is largely desirable. In brief, the attempt to expand our sample observations is inherently difficult due to the limited numbers of experts and professional in the relevant field in Taiwan. The aforementioned limitations would require extensive future research to either correct the defects or manage to mitigate its effects on the conclusions drawn therefrom.

\section{Conclusion: From Theory to Praxis}

As more and more countries around the globe embark upon the road to performance budgeting, a comprehensive understanding of the required conditions for this budgeting reform becomes critical for policy makers. In this 
research, we explore the question of whether the international experiences generated from the successful stories of advanced economies would also be recognized in the emerging markets. As an attempt to answer this question, our research fills the gap in the literature through conducting a case study in Taiwan. A survey instrument is also applied to collect qualitative data for further analysis. We further justify our survey results by conducting CFA analysis. We also firmly believe this research has successfully solicited information from individual officials from governments and experts from academia for the reference of more future studies.

According to our survey results, we conclude that the international experiences generated from the advanced economies are largely approved in Taiwan. Our empirical results reveal that the respondents from academia (usually with a doctoral degree) hold stronger, affirmative attitude towards these essential factors than their counterparts. This may be partly explained by the argument that the movement towards performance oriented budgeting is vigorously supported in academia. And most government practitioners play the role of followers. The outcome of our survey examination also suggests the difficulties of moving from theory to praxis, as suggested by Schick (2007). This may require further amendments in the reforms adopted by advanced economies or advocated by international organizations.

The general scores in our survey indicate high consensus in Taiwan over the issues as to how to properly implement performance budgeting. In view of such consensus, the professional training of government practitioners remains highly encouraged. The disparity between academic professionals (forerunners) and other field practitioners (followers) may lie in their understanding of performance budgeting; the more knowledge on performance budgeting, the more receptive to this budgeting reform movement. Hence, more professional training in performance budgeting would bridge the gap between forerunners and followers.

Other than performance budgeting knowledge level, the other possible explanation to the remarkably different attitude toward performance budgeting between academicians and budgeters lies in the responsibilities and workloads they have to assume. Executive budgeters are forced to be transparent fiscally and have to submit all sorts of evaluation paperwork and deal with practical difficulties while academicians are just external beneficiaries of all these budget reforms. Under this circumstance,

With respect to the problems relating to the lack of adequate human resources or management skills required for implementing such institutional reforms in the emerging markets, we believe this role can be adequately fulfilled by various international organizations. With the development of performance measurement strategies, as well as a thorough examination of performance budgeting practices, international organizations such as the World Bank, the IMF, and the OECD can provide expertise in implementing programs for performance budgeting, fiscal transparency, and the MTEF with well-established procedures. Accordingly, the emerging markets that are deficient in these areas should be encouraged to seek help from these international organizations to strengthen institutional requirements on the way towards a more performance oriented budgeting system.

\section{References}

Alesina, A., \& Roberto, P. (1996). Budget Deficits and Budget Institutions. NBER Working Paper 5556.

Alt, J., Lassen, D., \& Rose, S. (2006). The Causes of Fiscal Transparency: Evidence from the US States. IMF Staff Papers, 53(Special Issue), 30-57.

Arnold, W. (2008). Performance Budgeting: What Works, What Doesn 't. US: Management Concept.

Bentler, P., \& Chou, C. P. (1987). Practical Issues in Structural Modeling. Sociological Methods and Research, 16(1), 78-117. http://dx.doi.org/10.1177/0049124187016001004

Berman, E., \& Wang, X. H. (2000). Performance Measurement in US Counties: Capacity for Reform. Public Administration Review, 60(5), 409-420. http://dx.doi.org/10.1111/0033-3352.00104

Cheung, A. (2006). Budgetary reforms in two city states: impact on the central budget agency in Hong Kong and Singapore. International Review of Administrative Sciences, 72(3), 341-361. http://dx.doi.org/10.1177/0020852306068013

Cheung, G., \& Rensvold, R. (2002). Evaluating Goodness-of-Fit Indexes for Testing Measurement Invariance. Structural Equation Modeling, 9(2), 233-255. http://dx.doi.org/10.1207/S15328007SEM0902_5

Cho, J. (2004). Information Flow for Successful MTEF Operation and Its Implication for the Korea Government. The World Bank and Korea Development Institute Conference Proceedings (March 2004, pp. 279-298). Washington D.C.: World Bank.

Colton, D., \& Covert, R. (2007). Designing and Constructing Instruments for Social Research and Evaluation. San Francisco: Jossey-Bass. 
DeCoster, J. (1998). Overview of Factor Analysis. Retrieved August 27, 2011, from http://www.stat-help.com/hotes.html

Dorotinsky, B. (2004). Medium-Term Expenditure Frameworks, Performance, and Transparency. The World Bank and Korea Development Institute Conference Proceedings (March 2004, pp. 299-305). Washington D.C.: World Bank.

Fan, X., Thompson, B., \& Wang, L. (1999). Effects of Sample Size, Estimation Methods, and Model Specification on Structural Equation Modeling Fit Indexes. Structural Equation Modeling, 6(1), 56-83. http://dx.doi.org/10.1080/10705519909540119

Fornell, C., \& Larcker, D. (1981). Evaluating Structural Equation Models with Unobservable variables and Measurement Error: Algebra and Statistics. Journal of Marketing Research, 18(3), 382-388. http://dx.doi.org/10.2307/3150980

Gilmour, J., \& Lewis, D. (2006). Assessing Performance Budgeting at OMB: The Influence of Politics, Performance, and Program Size. Journal of Public Administration Research and Theory, 16(2), 169-186. http://dx.doi.org/10.1093/jopart/muj002

Houerou, P., \& Taliercio, R. (2002). Medium Term Expenditure Framework: From Concept to Practice. World Bank Working Paper No. 28. Washington D.C.: World Bank. Retrieved August 27, 2011, from http://www.worldbank.org/afr/wps/wp28.pef

Islam, R. (2006). Does More Transparency Go Along with Better Governance? Economics \& Politics, 18(2), 121-167. http://dx.doi.org/10.1111/j.1468-0343.2006.00166.x

Lee, R. (1997). A Quarter Century of State Budgeting Practices. Public Administration Review, 57(2), 133-140. http://dx.doi.org/10.2307/977061

Lee, J. Y., \& Wang, X. (2009). Assessing the Impact of Performance-Based Budgeting: A Comparative Analysis across the United States, Taiwan, and China. Pubic Administration Review, December, Special Issue, 62-68.

Little, T. (1997). Mean and Covariance Structures (MACS) Analyses of Cross-Cultural Data: Practical and Theoretical Issues. Multivariate Behavioral Research, 32(1), 53-76. http://dx.doi.org/10.1207/s15327906mbr3201_3

Loehlin, J. (1987). Latent Variable Models: An Introduction to Factor Path, and Structural Analysis. Hillsdale, NJ: Erlbaum.

MacCallum, R., \& Hong, S. (1987). Power Analysis in Covariance Structure Modeling Using GFI and AGFI. Multivariate Behavioral Research, 32(2), 193-210. http://dx.doi.org/10.1207/s15327906mbr3202_5

Melkers, J., \& Willoughby, K. (2005). Models of Performance-Measurement Use in Local Governments: Understanding Budgeting, Communication, and Lasting Effects. Public Administration Review, 65(2), 180-190. http://dx.doi.org/10.1111/j.1540-6210.2005.00443.x

Melkers, J., \& Willoughby, K. (2001). Budgeters' Views of State Performance-Budgeting Systems: Distinctions across Branches. Public Administration Review, 61(1), 54-64. http://dx.doi.org/10.1111/0033-3352.00005

Melkers, J., \& Willoughby, K. (1998). The State of the States: Performance-Based Budgeting Requirements in 47 out of 50. Public Administration Review, 58(1), 66-73. http://dx.doi.org/10.2307/976891

OECD. (2009). Evolutions in Budgetary Practice: Allen Schick and the OECD Senior Budget Officials. Paris: OECD.

OECD. (2008a). Performance Budgeting: A Users' Guide. OECD Observer, Mar 2008. Retrieved from http://www.oecd.org

OECD. (2008b). Sequencing and Pacing of Performance Budgeting Reform. Summary of the $5^{\text {th }}$ Annual Meeting of the SBO Network on Performance and Results, 27-28 Oct 2008, Paris: OECD.

Parry, T. (2008). Transparency Aids Latin American Growth. IMF Survey. Retrieved from http://www.imf.org/external/pubs/ft/survey/so/2008/CAR018A.htm

Roh, C. Y., Moon, M. J., \& Jung, C. (2010). Measuring Performance of US Nonprofit Hospitals: Do Size and Location Matter? Public Performance and Management Review, 34(1), 22-37. http://dx.doi.org/10.2753/PMR1530-9576340102

Schick, A. (2008). Getting Performance Budgeting to Perform. Retrieved from $\mathrm{http} / / /$ siteresources.worldbank.org/MEXICOEXTN/Resources/ConceptPaperAllenSchickFinal.pdf 
Schick, A. (2007). Performance Budgeting and Accrual Budgeting: Decision Rules or Analytic Tools? OECD Journal on Budgeting, 7(2), 109-138. http://dx.doi.org/10.1787/budget-v7-art11-en

Shah, A., \& Shen, C. (2007a). A Primer on Performance Budgeting. In A. Shah (Ed.), Budgeting and Budgetary Institutions (pp. 137-178). Washington D.C.: World Bank. http://dx.doi.org/10.1596/978-0-8213-6939-5

Shah, A. \& Shen, C. (2007b). Citizen-Centric Performance Budgeting at the Local Level. In A. Shah (Ed.), Local Budgeting (pp. 151-178). Washington D.C.: World Bank. http://dx.doi.org/10.1596/978-0-8213-6945-6

Sterck, M. (2007). The Impact of Performance Budgeting on the Role of the Legislature: A Four-country Study. $\begin{array}{llll}\text { International Review of Administrative } & \text { Sciences, } & 73(2), & 189-203 .\end{array}$ http://dx.doi.org/10.1177/0020852307077960

Su, T. T. (2007). Public Budgeting Reform in Taiwan. In G. Caiden \& T. T. Su (Eds.), The Repositioning of Public Governance: Global Experience and Challenges (pp. 321-345). Taipei: Best-Wise Publishing.

Torkzadeh, G., Koufteros, X., \& Pflughoeft, K. (2003). Confirmatory Analysis of Computer Self-Efficacy. Structural Equation Modeling, 10(2), 263-275. http://dx.doi.org/10.1207/S15328007SEM1002_6

Wang, X. H. (2002). Assessing Performance Measurement Impact: A Study of U.S. Local Governments. Public Performance \& Management Review, 26(1), 26-43. http://dx.doi.org/10.2307/3381296

Willoughby, K., \& Melkers, J. (2000). Implementing PBB: Conflicting Views of Success. Public Budgeting and Finance, 20(1), 105-120. http://dx.doi.org/10.1111/0275-1100.00006

World Bank. (1998). Public Expenditure Management Handbook. Washington D.C.: World Bank.

\section{Notes}

Note 1. Su (2007) maintains that MTPBS is just like the role of Government Performance and results Act (GPRA) in the United States.

Note 2. AGFI (Adjusted Goodness-of-Fit Index) value is recommended to be larger than 0.9. However, MacCallum \& Hong (1997) suggest that AGFI value larger than 0.8 is also acceptable.

\section{Copyrights}

Copyright for this article is retained by the author(s), with first publication rights granted to the journal.

This is an open-access article distributed under the terms and conditions of the Creative Commons Attribution license (http://creativecommons.org/licenses/by/3.0/). 
Appendix I: Statistical Results of Survey

\begin{tabular}{lcc}
\hline \multicolumn{1}{c}{ Questions } & MEAN & SD \\
\hline I. Perception & $\mathbf{3 . 7 3}$ & $\mathbf{0 . 8 1}$ \\
PERC1. How do you perceive performance budgeting? & 3.71 & 0.81 \\
$\begin{array}{l}\text { PERC2. Do you know that performance budgeting is widely implemented } \\
\begin{array}{l}\text { in OECD member countries? } \\
\text { PERC3. Do you think performance budgeting should also be actively } \\
\text { implemented in Taiwan? }\end{array}\end{array}$ & 3.47 & 0.86 \\
\hline II. Fiscal/Budgeting Transparency & & 0.66 \\
\hline
\end{tabular}

FT1. Policy and management roles with the public sector should be clear and publicly disclosed as this is necessary to successfully implement performance budgeting.

FT2. A clearly defined government asset-liability management is necessary to successfully implement performance budgeting.

$3.90 \quad 0.55$

FT3. The same accounting policies used for all fiscal reports are necessary to successfully implement performance budgeting.

FT4. Government activities and finances should be internally audited, and audit procedures should be open for review as these are necessary to successfully implement performance budgeting.

\section{Medium-Term Expenditure Framework (MTEF)}

MTEF1. A macroeconomic model that projects revenue and expenditure in the medium term is necessary to successfully implement performance budgeting.

3.72

0.58

MTEF2. All ministries should calculate their medium-term program and provide the data to the Ministry of Finance for developing an expenditure ceiling as this is necessary to successfully implement performance budgeting.

MTEF3. Ministry of Finance should develop a MTEF for future projections of the expenditure ceiling in all ministries as this is necessary to successfully implement performance budgeting.

MTEF4. Ministry of Finance should hold a forum on the MTEF periodically as a communication platform for all ministries as this is necessary to successfully implement performance budgeting.

\section{Other Institutional Arrangements}

0.66

OTHER1. The support and assurance of agency leaders is necessary to successfully implement performance budgeting.

OTHER2. Professional capabilities among the agency staff are necessary to successfully implement performance budgeting.

$3.71 \quad 0.56$

$\begin{array}{ll}3.87 & 0.86\end{array}$

$4.15 \quad 0.77$

$4.45 \quad 0.70$

OTHER3. The organizational culture of being customer-oriented is necessary to successfully implement performance budgeting.

$3.71 \quad 0.67$

OTHER4. Performance evaluation involving citizen participation is necessary to successfully implement performance budgeting.

\section{Personal Information}

3.19

0.72

$\mathbf{N}$

(\%)

\section{Gender}




\section{Education}

High School and Below

Bachelor degree

$6 \quad 5.36 \%$

Masteral degree

$61 \quad 54.46 \%$

Doctoral degree

$24 \quad 21.43 \%$

Professional Experience with Budgeting

$1 \sim 5$ years

$6 \sim 10$ years

$37.50 \%$

$11 \sim 15$ years

$48 \quad \mathbf{4 2 . 8 6 \%}$

16 years and above

$13 \quad 11.61 \%$

Professional Field

Executive (OMB-like Agency)

$35 \quad 31.25 \%$

Legislative (CBO-like Agency)

$33 \quad 29.46 \%$

Control (GAO-like Agency)

$22 \quad 19.64 \%$

Academics

$22 \quad 19.64 \%$ 